\title{
Effect of Manganese Phosphating on Properties of 45 Steel Used for Gear Production
}

\author{
Xu Chen $^{1,2}$ \\ ${ }^{1}$ Department of Mechanical Engineering, Hebei University of Architecture, Zhangjiakou 075000, \\ China; \\ ${ }^{2}$ Department of Mechanical \& Automotive Engineering, Jeonju University, 55069, South Korea; \\ "E-mail: chenxu9000@163.com
}

Received: 10 November 2021 / Accepted: 28 December 2021 / Published: 2 February 2022

\begin{abstract}
Phosphating technology was utilized to improve the corrosion resistance and wear resistance of gear, allowing it to last significantly longer. The phosphating film formed on the gear surface was described and examined in terms of appearance, surface morphology, composition, thickness, corrosion resistance, and wear resistance. The results show that the appearance of the gear treated with conventional manganese phosphating or manganese composite phosphating is both black. However, after the treatment of manganese composite phosphating, many PTFE particles doping on the grains and gaps play a physical filling role. The PTFE has self lubrication performance with higher impedance which could block the penetration of corrosive medium and form a layer of solid lubricating film to greatly reduce corrosion and wear. The gear that has been phosphated with manganese composite solution offers the best corrosion resistance and wear resistance.
\end{abstract}

Keywords: Gear; Manganese composite phosphating; Corrosion resistance; Wear resistance

\section{FULL TEXT}

(C) 2022 The Authors. Published by ESG (www.electrochemsci.org). This article is an open access article distributed under the terms and conditions of the Creative Commons Attribution license (http://creativecommons.org/licenses/by/4.0/). 